\section{As Sociedades Caboclas na Amazônia: Tradição e Modernidade}

\section{Por José Luiz de Andrade Franco}

Doutor em História pela Universidade de Brasília. Pesquisador Associado do Centro de Desenvolvimento Sustentável da Universidade de Brasília (jldafranco@terra.com.br)

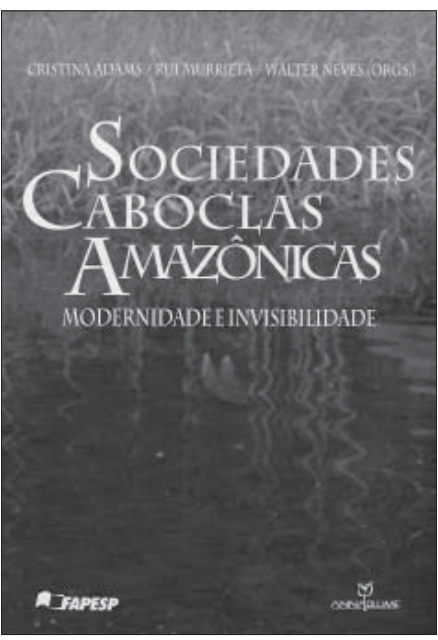

ADAMS, Cristina; MURRIETA, Rui; NEVES, Walter (Orgs.). Sociedades Caboclas Amazônicas: Modernidade e Invisibilidade. São Paulo: Annablume, 2006. 364 p.

O livro "Sociedades Caboclas Amazônicas: Modernidade e Invisibilidade", organizado por Cristina Adams, Rui Murrieta e Walter Neves, é o resultado de um workshop realizado pela Universidade de São Paulo (USP), sob o patrocínio da Fundação de Amparo à Pesquisa do Estado de São Paulo (FAPESP) e da Pró-Reitoria de Pesquisa, com o objetivo de promover, a partir de uma perspectiva multidisciplinar, um debate sobre as abordagens relacionadas com a investigação do campesinato histórico ou caboclo da Amazônia. Os artigos reunidos no livro, ao mesmo tempo em que fazem uma revisão crítica da literatura existente sobre o assunto, trazem dados de pesquisas recentes e propõem novas interpretações.

A principal intenção dos organizadores e autores dos artigos que compõem o livro é de dar visibilidade às sociedades caboclas da Amazônia, neste caso, por meio da produção de conhecimento acadêmico-científico sobre elas. Há um aspecto pragmático na tarefa, que ultrapassa a pura elucubração acadêmica. Trata-se de instrumentalizar a compreensão gerada por estes estudos para garantir ações mais eficazes da parte de movimentos sociais e organizações não governamentais envolvidas com a luta pela inclusão social das populações caboclas amazônicas, bem como políticas públicas mais bem informadas e, conseqüentemente, mais eficientes.

Um ponto de partida importante para as análises apresentadas no livro é a busca por romper com a perspectiva de que as sociedades caboclas sejam absolutamente limitadas por fatores naturais. Surge daí uma realidade amazônica que não é só natureza, mas também história. Isto conduz a uma ênfase nas particularidades locais e históricas das comunidades estudadas.

Há, também, a percepção de fatores comuns relevantes, dentre os quais se destaca a flexibilidade das sociedades caboclas amazônicas, o que marca a capacidade delas de se adaptarem a demandas de mercado, que ora se expandem ora se contraem. Desse modo, a inserção em uma economia de mercado e a economia de subsistência convivem, alternando-se o peso de cada uma delas devido a particularidades sócio-econômicas e históricas. É isto que faz com que as sociedades caboclas amazônicas sejam, ao mesmo tempo, tradicionais e modernas.

Definidas como sociedades camponesas históricas, as sociedades caboclas, como um produto do processo de colonização européia, têm sido, muitas vezes, excluídas das análises antropológicas por serem percebidas como um "outro incompleto" em relação aos "outros originais" representados pelas populações indígenas da Amazônia. Todavia, Adams, Murrieta e Neves (p. 16) argumentam que mesmo estes "outros originais", contra os quais os caboclos são comparados desfavoravelmente, são o resultado do processo histórico de colonização.

Fica clara, nos artigos do livro, a impossibilidade de sustentação da idealização das sociedades caboclas e indígenas como grupos pré-modernos capazes de resistir às influências da modernidade, afirmando suas tradições, supostamente harmônicas com o ambiente natural e sem

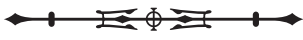


contradições sociais, ou seja, como "bons selvagens" ahistóricos. Por outro lado, surge a imagem de sociedades capazes de lutar e de garantir, no decorrer do processo histórico, certo grau de autonomia nos seus espaços de experiências vividas e na sua capacidade de projetar horizontes de expectativas.

Há uma interessante discussão conceitual a respeito da palavra "caboclo", que seria imprópria para se referir a uma população tão heterogênea como os camponeses históricos amazônicos. Somado a isto, existe o fato de que a palavra teve e tem, eventualmente, um uso pejorativo, ambíguo e relacional, com implicações racistas e segregadoras. No entanto, o termo tem se prestado a apropriações diversas na estruturação de um contra discurso, marcador da identidade mestiça amazônica, presente nos cenários sociais, políticos e artísticos da região. Por esse motivo, Murrieta, Neves, Barretto Filho e Adams (p. 352) defendem o uso do termo "caboclo" como um conceito em reconstrução e ressignificação, capaz de incorporar uma identificação positiva sobre um modo de vida intimamente ligado à paisagem sócioecológica amazônica.

Além de uma Introdução - assinada pelos organizadores - e de uma Conclusão - elaborada por Rui Murrieta, Walter Neves, Henyo Barretto Filho e Cristina Adams - discutindo aspectos teóricos e metodológicos presentes durante o workshop realizado na USP e que perpassam todos os artigos, o livro é dividido em cinco seções. A primeira delas, "Identidade, História e Sociedade", traz quatro artigos, iniciando-se com "Utopias e distopias na paisagem social amazônica", de Stephen Nugent. Trata-se, sobretudo, de uma crítica à naturalização ideológica das populações que vivem na Amazônia, sejam elas indígenas ou caboclas, característica de uma boa parte da produção antropológica sobre estas sociedades. Para o autor, os sistemas agrários das sociedades caboclas - na sua terminologia, do campesinato histórico da Amazônia - são "experimentos" neocoloniais, baseados, em grande medida, em massas populacionais alienígenas à região e envolvidas no avanço da fronteira de ocupação da terra. O segundo artigo, de William Balée, "Transformação da paisagem e mudanças da língua: um estudo de caso em ecologia histórica amazônica", mostra, a partir do estudo do cacau como produto de exportação na Amazônia do século XVIII, a influência da colonização e do sistema europeu de finanças e de comércio sobre a alteração do vocabulário e sobre as percepções relacionadas com a paisagem e a biota amazônicas, ressaltando a importância dos processos históricos na formação das sociedades caboclas e nas sociedades indígenas. Décio Alencar Guzmán, em "Índios misturados, caboclos e curibocas: análise histórica de um processo de mestiçagem, Rio Negro (Brasil), séculos XVIII e XIX", analisa o processo de mestiçagem entre indígenas, europeus e africanos como parte de um conjunto de estratégias postas em prática pela Coroa portuguesa visando à exploração dos recursos humanos existentes na América lusitana. O último artigo da seção, "Presente ambivalente: uma maneira amazônica de estar no tempo", de Mark Harris, chama a atenção para a capacidade das populações ribeirinhas de se adaptarem às vicissitudes dos seus contextos socioeconômicos, especialmente à dinâmica de boom-bust (expansão e contração), que faz com que elas oscilem entre períodos de maior inserção na economia de mercado e períodos de retração para a economia de subsistência, demonstrando flexibilidade e abertura diante do novo. Esta seria uma habilidade desenvolvida pelas sociedades caboclas para negociar com as condições que se apresentam a cada momento presente, sem dar maior importância a um passado remoto.

\section{A seção "Sustentabilidade e Políticas de} Desenvolvimento" é composta de três artigos. "Populações tradicionais: introdução à crítica da ecologia política de uma noção", de Henyo Barretto Filho, demonstra a dificuldade que o conceito de populações tradicionais traz para a análise das populações que habitam os ecossistemas amazônicos, tornando-as reféns de uma definição que não leva em conta as estratégias de adaptação desenvolvidas por elas, os processos históricos ocorridos na região 
e nem a complexidade e amplitude dos impactos e transformações que elas impuseram à hiléia. $\bigcirc$ autor propõe o uso do termo "populações residentes", mais includente e flexível, capaz de, na luta por direitos destas populações, dar sentido às demandas pelos recursos materiais e serviços característicos da modernidade. Deborah de Magalhães Lima, em "A economia doméstica em Mamirauá", estuda a economia das unidades domésticas da Reserva de Desenvolvimento Sustentável de Mamirauá, no Alto Amazonas, demonstrando a importância dos laços de parentesco sanguíneos e fictícios na estruturação das relações sociais e na produção da sobrevivência material das populações ribeirinhas. A autora discute a busca por melhores condições de vida e a convivência com o risco enfrentada pelas comunidades ribeirinhas, questionando a ênfase que os projetos de desenvolvimento sustentável dão às variáveis ambientais e alertando para o fato de que isto pode vir a reproduzir indefinidamente baixos padrões de produção e consumo, bem como desigualdades sociais. Ainda nesta seção, o artigo "Economia familiar cabocla na várzea do Médio-Baixo Amazonas", de Fabio de Castro, por meio de ampla análise, envolvendo 172 comunidades e 8.570 unidades domésticas de ribeirinhos, mostra como as quatro principais atividades econômicas das populações do Médio-Baixo Amazonas - pesca, agricultura, criação de gado e trabalho assalariado/aposentadoria - se combinam e como a importância de cada uma delas varia de comunidade para comunidade, ou mesmo entre unidades domésticas distintas, o que indica um quadro socioeconômico de grande heterogeneidade.

Dois artigos compõem a seção "Manejo de Recursos". "Intensificação agrícola, identidade econômica e invisibilidade entre pequenos produtores rurais amazônicos: caboclos e colonos numa perspectiva comparada", de Eduardo Brondízio, demonstra como os sistemas de produção agrícola dos pequenos produtores rurais amazônicos, sejam caboclos ou colonos, se baseiam na co-existência de atividades intensivas e extensivas, que visam minimizar riscos e consolidar a propriedade rural, bem como expandir as atividades voltadas para o mercado. Célia Futemma, no artigo "Uso e acesso aos recursos florestais: os caboclos do Baixo Amazonas e seus atributos sócio-culturais", analisa o papel das redes sociais, baseadas no parentesco e na vizinhança, na exploração dos recursos naturais da várzea e da terra-firme por parte da comunidade ribeirinha de Patos, no Baixo Amazonas. Ela enfatiza o fato de que, sobrepostas às regras formais do Estado, que implementou a reforma agrária na região, existem regras informais de acesso e uso dos recursos florestais, que promovem a acomodação da diversidade social e paisagística, minimizando as desigualdades entre os pequenos produtores.

Na seção "Gênero e Vida Cotidiana" estão mais dois artigos. O primeiro deles, "Mulheres, relações de gênero e tomadas de decisão em unidades domésticas caboclas do estuário amazônico", de Andréa Siqueira, trata, a partir do estudo de unidades familiares em comunidades localizadas no município de Ponta de Pedras, na Ilha de Marajó, da capacidade das mulheres de influenciar nas decisões domésticas, o que é afetado, sobretudo, pelos seguintes fatores: tipo de direito que elas têm sobre a terra, contribuição econômica efetiva e nível de escolaridade. O segundo artigo, “'Eu adoro flores!': gênero, estética e experimentação agrícola em quintais", de Rui Murrieta e Antoinette WinklerPrins, demonstra as motivações sociais, ecológicas, econômicas e emocionais implicadas no cultivo de jardins e quintais por um grupo de mulheres da llha de Ituqui, no Baixo Amazonas.

A última seção do livro, "Dieta e Saúde", também traz dois artigos. "O pão da terra: da invisibilidade da mandioca na Amazônia", de Cristina Adams, Rui Murrieta, Andréa Siqueira, Walter Neves e Rosely Sanches, estuda a dieta e a ingestão de calorias e proteínas em cinco comunidades nas Ilhas de Marajó (estuário) e Ituqui (Baixo Amazonas), discutindo as implicações da associação entre farinha de mandioca e peixe como principal sustentáculo da subsistência das populações ribeirinhas. Por fim, o artigo de Hilton Pereira da Silva, "Sócio-ecologia da saúde 
e da doença: os efeitos da invisibilidade nas populações caboclas da Amazônia", avalia, a partir do estudo de quatro comunidades ribeirinhas amazônicas (Caxiuanã, Aracampina, Santana e Praia Grande), os altos índices de subnutrição e infecção por parasitas intestinais nas populações caboclas.

Os trabalhos apresentados no livro são contribuições importantes para dar visibilidade às populações caboclas da Amazônia, na medida em que explicitam os sentidos, as motivações e disposições implicadas na complexa realidade sócio-ambiental amazônica. A compreensão desta realidade permite ampliar os horizontes do debate em torno de questões relacionadas com a conservação da biodiversidade e da sociodiversidade na Amazônia, e também com os modelos de desenvolvimento pretendidos para a região. 